Proc. of the XI Int. Conf. - Ion Implantation and other Applications of Ions and Electrons, Kazimierz Dolny 2016

\title{
Effect of Structure on Physicomechanical Properties of Transition Metals Diboride Films
}

\author{
A.A. Goncharov ${ }^{a, *}$, A.N. Yunda ${ }^{a}$, H. Komsta ${ }^{b}$ And P. Rogalski ${ }^{b}$ \\ ${ }^{a}$ Sumy State University, Rimsky-Korsakov 2, 40007 Sumy, Ukraine \\ ${ }^{b}$ Lublin University of Technology, Nadbystrzycka 36-38A, 20-618 Lublin, Poland
}

\begin{abstract}
Research of the effect of structure on composition and physicomechanical properties of transition metals diboride films deposited by RF-magnetron sputtering was carried out. It was shown that there is a wide range of different structures, from amorphous to nanocrystalline one with 1-40 nm nanocrystallite sizes in the case of transition metals diboride films. The correlation between the structure, composition, and physicomechanical properties of transition metals diboride films was established.
\end{abstract}

DOI: 10.12693/APhysPolA.132.270

PACS/topics: transition metal diborides, nanocomposite coating, magnetron sputtering, structural state, hardness, elastic modulus

\section{Introduction}

Transition metals diboride film coatings $\left(\mathrm{TiB}_{2}, \mathrm{CrB}_{2}\right.$, $\mathrm{TaB}_{2}, \mathrm{HfB}_{2}$ ) are actively investigated due to their useful physical and mechanical characteristics. Compounds of this type have a high melting temperature, therefore their synthesis in a film state is performed by magnetron sputtering (RF and $\mathrm{DC})$. At the same time, synthesis features of transition metal nitrides and carbides film materials are manifested in dependence of the formed structure and properties on the incident ions energy and the substrate temperature which leads to the formation of film condensates of different structural states amorphous, cluster, or nanocrystalline [1,2].

In this study, RF magnetron sputtering of targets in an argon atmosphere was used for the deposition of transition metals (Hf and Ta) diborides thin films. The method of RF-magnetron sputtering allows to vary widely the composition, structure and physicomechanical properties of transition metal diborides thin films.

The aim of this work is the study of the size factor effect on the composition and physicomechanical characteristics of transition metals diboride films.

Tantalum and hafnium diborides thin films were deposited by no-reactive RF-magnetron sputtering $(13.56 \mathrm{MHz})$ at argon pressure of $0.56-0.64 \mathrm{~Pa}$, at a constant generator power of $500 \mathrm{~W}$, at different substrate biases and substrate temperatures. Discs of $120 \mathrm{~mm}$ diameter were used as targets. The films were deposited on a substrate $20 \times 5 \times 5 \mathrm{~mm}^{3}$ in size made of AISI 302 stainless steel.

The film thickness controlled by multibeam interferometry using a MII-4 interferometer was varied from 1 to $2 \mu \mathrm{m}$. The structure and phase composition of the coatings were examined using a DRON-3 diffractometer in

\footnotetext{
* corresponding author; e-mail: ○.goncharov@mss. sumdu. edu.ua
}

$\mathrm{Cu} K_{\alpha}$-radiation (Ni-filter). The mechanical tests were performed on nanohardness Nano Indenter II (MTS Systems Corporation USA) equipped with a Berkovich indenter. Hardness and elastic modulus were found by analyzing the curve of indenter unloading by the standard method.

\section{Results and discussions}

As shown in Refs. [3-8], the most characteristic structure feature of transition metals diboride films synthesized by physical vapor deposition (PVD)-methods is a columnar morphology with a growth texture in plane (00.1). The X-ray diffraction patterns of tantalum and hafnium diborides films with the growth texture (00.1) are shown in Figs. 1 and 2. The intensities ratio of the diffractometric peaks in Figs. 1a,b and 2a,b shows that films have a different degree of texture. The most strongly expressed texture of films is shown in Fig. 1a and Fig. 2a. As the research results show [9], the energy conditions of magnetron sputtering (DC and RF) are optimum at the substrate bias of $-50 \mathrm{~V}$ for $\mathrm{DC}$ and $\pm 50 \mathrm{~V}$ for $\mathrm{RF}$, and at the substrate temperature of $\approx 550{ }^{\circ} \mathrm{C}$. Hafnium and tantalum diborides films were deposited at a positive bias potential applied to substrate holder and at a substrate temperature of $\approx 500{ }^{\circ} \mathrm{C}$.

A similar pattern for other diborides was observed by many authors: for the $\mathrm{TiB}_{2}$ films in $[3,10], \mathrm{CrB}_{2}[5,6]$ and others. The general features of substructural characteristic of the described films and their properties (Table I) were observed. A significant increase in the parameter $c$ indicates a growth of the concentration of dissolved boron atoms in the transition metal diborides lattice.

The results of comparative analysis of the composition and physicomechanical characteristics of transition metal diborides films having a columnar structure and the growth texture in the plane [00.1] are shown in Table I, and reveal the relationship between the physicomechanical properties and composition of formed films.

Highly-textured transition metal diborides films deposited at the bias potential of $-50 \mathrm{~V}$ (DC) or 


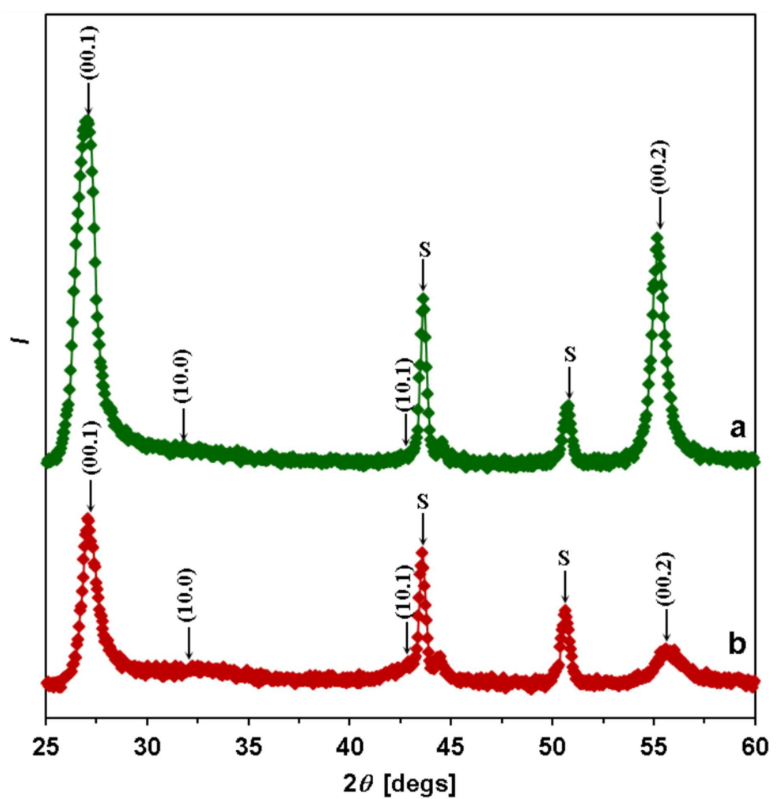

Fig. 1. X-ray diffraction patterns of tantalum diboride films with the growth texture (00.1): (a) highlytextured nanocrystalline over-stoichiometric film; (b) weakly-textured nanocrystalline stoichiometric film. S — the substrate reflections.

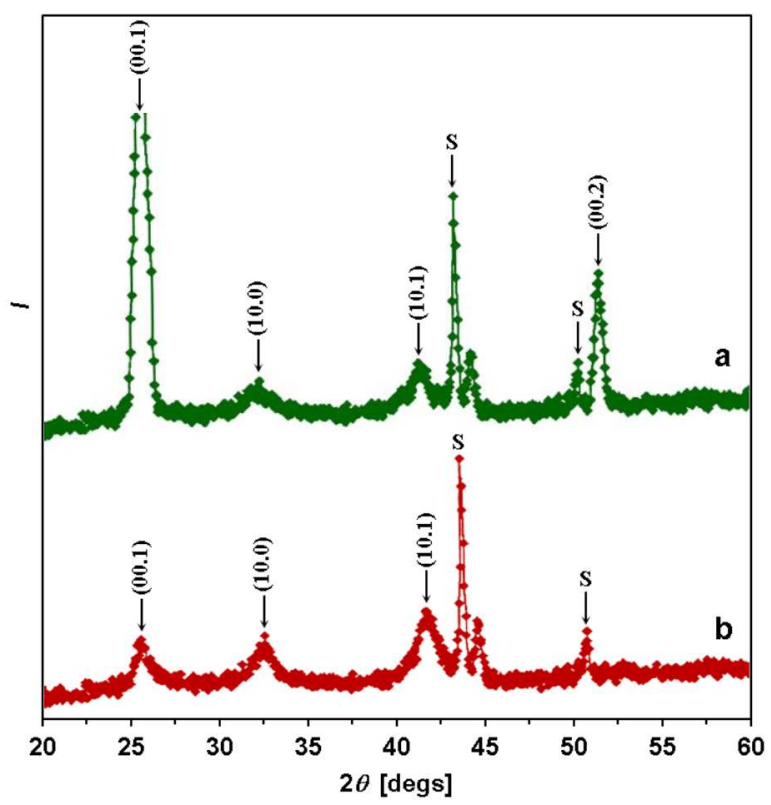

Fig. 2. As in Fig. 1, but for hafnium diboride.

$+50 \mathrm{~V}(\mathrm{RF})$ and at the substrate temperature of 500$550{ }^{\circ} \mathrm{C}[6,8,10,12]$ have the highest nanohardness values: $H v=44 \mathrm{GPa}\left(\mathrm{CrB}_{2}\right), 44 \mathrm{GPa}\left(\mathrm{HfB}_{2}\right), 48.5 \mathrm{GPa}\left(\mathrm{TiB}_{2}\right)$, $44 \mathrm{GPa}\left(\mathrm{TaB}_{2}\right)$. The investigations of composition show an increase in the boron concentration for $\mathrm{TiB}_{2}[3,4,11]$, $\mathrm{TaB}_{2}$ and $\mathrm{HfB}_{2}$ within the atomic concentration of bo- ron $\mathrm{B} / \mathrm{Me}=2.2-2.6$, which is probably associated with the features of electronic structure of transition metal diborides films that leads to an increase of nanohardness in comparing with the stoichiometric films (Table II, Figs. $1 \mathrm{~b}$ and $2 \mathrm{~b})$, respectively $H v=33 \mathrm{GPa}\left(\mathrm{CrB}_{2}\right)$, $36 \mathrm{GPa}\left(\mathrm{HfB}_{2}\right), 37 \mathrm{GPa}\left(\mathrm{TiB}_{2}\right), 35 \mathrm{GPa}\left(\mathrm{TaB}_{2}\right)$.

Applying a negative bias potential of $-25 \mathrm{~V}$ at a substrate temperature of $\approx 300^{\circ} \mathrm{C}$ leads to the formation of amorphous-crystalline films [20] of tantalum and hafnium diborides (Fig. 3). Significant broadening of the diffraction peaks with simultaneous reduction of their intensity was observed after the films formation. There was an increase of the parameter $a$ and a decrease of the parameter $c$. In this case the grain size was $\approx 5-10 \mathrm{~nm}$. The formation of transition metal diborides films of understoichiometric composition occurs for the amorphouscrystalline films. This leads to a further decrease of hardness and elastic modulus for $\mathrm{HfB}_{2}$ (26 and $254 \mathrm{GPa}$, respectively) and $\mathrm{TaB}_{2}$ (29.4 and $\left.232 \mathrm{GPa}\right)$, respectively.

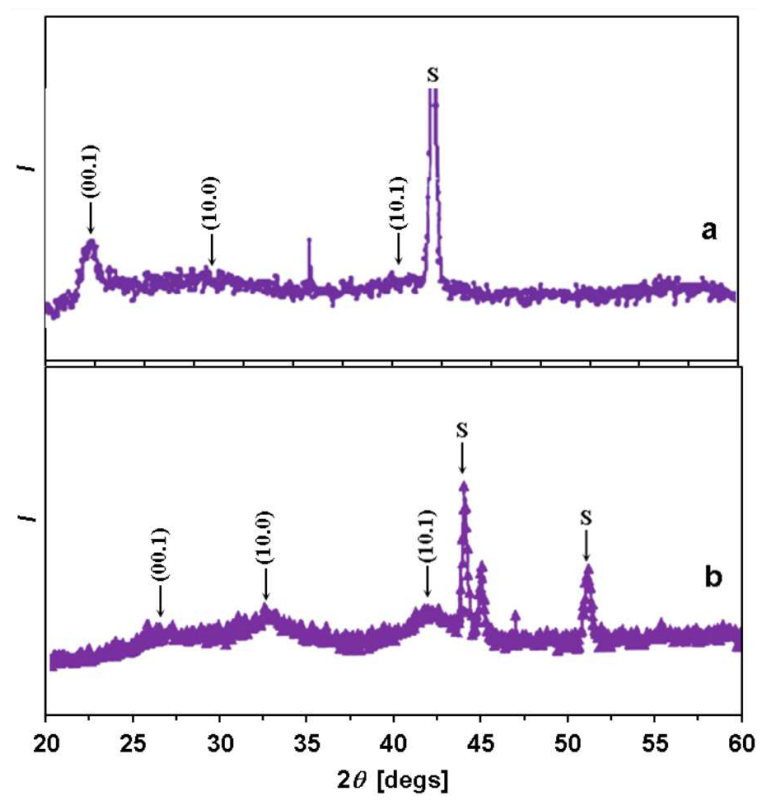

Fig. 3. X-ray diffraction patterns of clustered tantalum (a) and hafnium (b) diborides films. $\mathrm{S}$ - the substrate reflections.

Halo-curves corresponding to the diffraction peaks (00.1) and (10.0) in amorphous-crystalline state (Fig. 3) merge into a single one (Fig. 4), which leads to the formation of an amorphous films with nanocrystallites size less than $1 \mathrm{~nm}$. Further reduction of the atomic concentration of boron B/Me occurs for amorphous films [14, 15]. This can be explained by a large number of ragged and not formed chemical bonds, which ultimately leads to significant reduction of hardness up to $13 \mathrm{GPa}\left(\mathrm{HfB}_{2}\right)$ and 11.5 $\mathrm{GPa}\left(\mathrm{TaB}_{2}\right)$, and therefore to reduction of elastic modulus - up to $187 \mathrm{GPa}\left(\mathrm{HfB}_{2}\right)$ and $144 \mathrm{GPa}\left(\mathrm{TaB}_{2}\right)$. 
Substructural characteristics of over-stoichiometric transition metal diborides films.

\begin{tabular}{|c|c|c|c|c|c|c|c|c|c|}
\hline \multirow[b]{2}{*}{ Target } & \multicolumn{5}{|c|}{ Crystal lattice parameters [nm] } & \multirow[b]{2}{*}{ 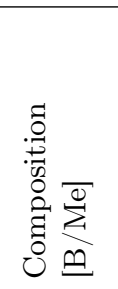 } & \multirow[b]{2}{*}{ 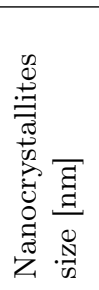 } & \multirow[b]{2}{*}{ 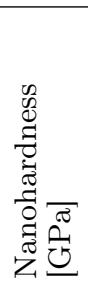 } & \multirow[b]{2}{*}{ 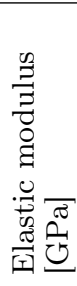 } \\
\hline & $a^{*}$ & $a$ & $c^{*}$ & $c$ & $c / a$ & & & & \\
\hline $\mathrm{TiB}_{2}[11]$ & - & - & 0.323 & 0.325 & - & 2.4 & 20 & 48.5 & 400 \\
\hline $\mathrm{HfB}_{2}[12]$ & 0.314 & 0.317 & 0.347 & 0.351 & 1.107 & $2.2-2.6$ & $20-30$ & 44 & 396 \\
\hline $\mathrm{CrB}_{2}[13]$ & 0.297 & - & 0.307 & - & - & 2.4 & $20-50$ & 43.9 & 397 \\
\hline $\mathrm{TaB}_{2}[10]$ & 0.309 & 0.312 & 0.322 & 0.327 & 1.046 & $2.2-2.6$ & $38-42$ & 44 & 348 \\
\hline
\end{tabular}

${ }^{*}$ Data file JCPDS

Structure, composition, substructural and physicomechanical properties

TABLE II of stoichiometric transition metal diborides films.

\begin{tabular}{|c|c|c|c|c|c|c|c|c|}
\hline \multirow[b]{2}{*}{ Target } & \multicolumn{4}{|c|}{ Crystal lattice parameters [nm] } & \multirow{2}{*}{ 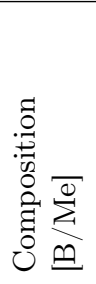 } & \multirow{2}{*}{ 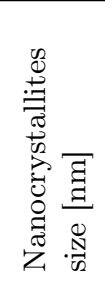 } & \multirow{2}{*}{ 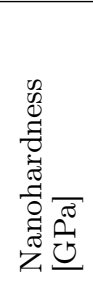 } & \multirow{2}{*}{ 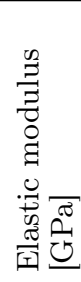 } \\
\hline & $a^{*}$ & $a$ & $c^{*}$ & $c$ & & & & \\
\hline $\mathrm{TiB}_{2}[16,17]$ & - & - & - & - & 2.0 & 20 & 36 & 365 \\
\hline$(\mathrm{W}, \mathrm{Ti}) \mathrm{B}_{2}[19]$ & - & - & - & - & 2.0 & 50 & 37 & 389 \\
\hline $\mathrm{HfB}_{2}[12]$ & 0.314 & 0.316 & 0.347 & 0.346 & 2.0 & $15-20$ & 36 & 340 \\
\hline $\mathrm{CrB}_{2}[18]$ & 0.297 & 0.297 & 0.307 & 0.306 & 2.0 & $20-40$ & 33 & 276 \\
\hline $\mathrm{TaB}_{2}[10]$ & 0.3098 & 0.3093 & 0.3226 & 0.322 & 1.96 & $17-19$ & 35 & 266 \\
\hline
\end{tabular}

${ }^{*}$ Data file JCPDS

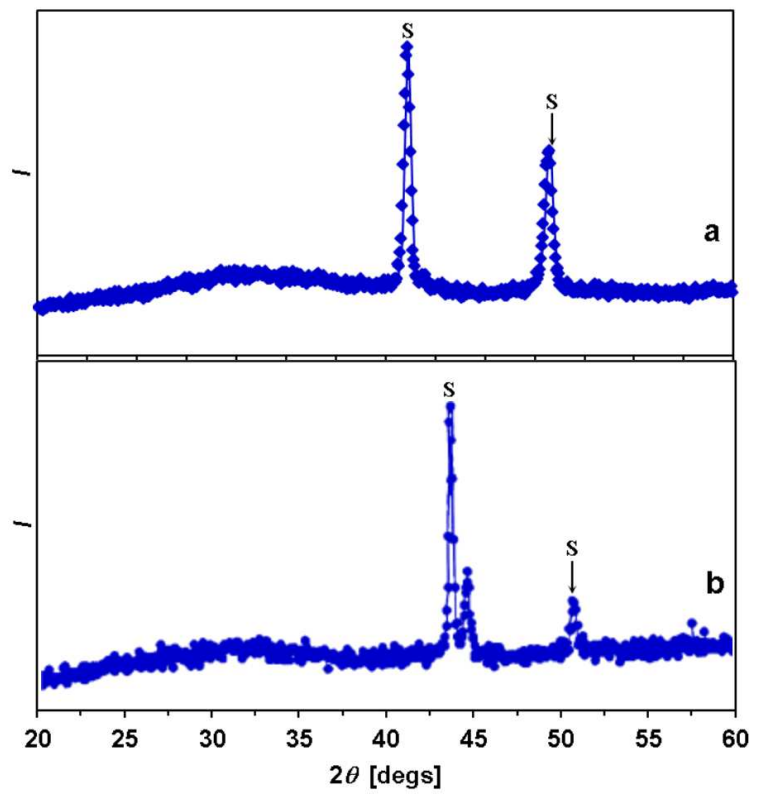

Fig. 4. X-ray diffraction patterns of amorphous tantalum (a) and hafnium (b) diborides films. $\mathrm{S}$ - the substrate reflections.

\section{Conclusions}

Analysis of the effect of structure on the physicomechanical properties of transition metal diborides films allows to distinguish four groups of films:

- highly-textured $\left(2^{\circ}<\Delta \varphi<10^{\circ}\right)$ nanocrystalline, over-stoichiometric superhard films with a crystallite size of $20-50 \mathrm{~nm}$;

- weakly-textured $\left(10^{\circ}<\Delta \varphi<20^{\circ}\right)$ nanocrystalline, stoichiometric films with the crystallite size 10-20 nm;

- non-textured, nanocrystalline, understoichiometric films with the crystallite size $5-10 \mathrm{~nm}$;

- amorphous films with the crystallite size less than $1 \mathrm{~nm}$.

The comparative analysis of the physicomechanical properties shows that the indicators of overstoichiometric coatings excel the indicators of stoichiometric films. Over-stoichiometric coatings have the best physicomechanical characteristics, high hardness value and a relatively low elastic modulus. This fact gives 
grounds to assume that the over-stoichiometric coatings have the highest wear resistance compared to those having a lower degree of texture. The formation of understoichiometric amorphous or amorphous-crystalline transition metal diboride films occurs if the energy supplied to the growing film is not enough to stimulate its crystallization, thus the values of nanohardness and elastic modulus are much smaller than for nanocrystalline films.

Thus, the level of physicomechanical properties of considered nanocomposite coatings is largely caused by nanodimensionality of their grain structure.

\section{Acknowledgments}

This paper was prepared within the framework of the budget theme No. 0116U002621 "Physical bases of the formation of the structure and properties of nanostructured transition metal borides, nitrides and boridonitrides films for application in mechanical engineering".

\section{References}

[1] A.D. Pogrebnjak, I.V. Yakushchenko, V.M. Beresnev, A.I. Kupchishin, O.V. Bondar, M.A. Lisovenko, H. Amekura, K. Kono, K. Oyoshi, Y. Takeda, Tech. Phys. 60, 1176 (2015).

[2] A.D. Pogrebnjak, B.A. Postol'nyi, Yu.A. Kravchenko, A.P. Shipilenko, O.V. Sobol', V.M. Beresnev, A.P. Kuz'menko, J. Superhard Mater. 37, 101 (2015).

[3] F. Kunc, J. Musil, P.H. Mayrhofer, C. Mitterer, Surf. Coat. Technol. 174-175, 744 (2003).

[4] P.H. Mayrhoffer, C. Mitterer, J.G. Wen, J.E. Greene, I. Petrov, J. Appl. Phys. Lett. 86, 131909 (2005).

[5] P.H. Mayrhoffer, C. Mitterer, L. Hultman, H. Clements, Progr. Mater. Sci. 51, 1032 (2006).

[6] M. Zhou, M. Nose, Y. Makino, K. Nogi, Thin Solid Films 359, 165 (2000).
[7] W. Herr, E. Broszeit, Surf. Coat. Technol. 97, 335 (1997).

[8] K.L. Dahm, L.R. Jordan, J. Haase, P.A. Dearnley, Surf. Coat. Technol. 108-109, 413 (1998).

[9] A.A. Goncharov, Phys. Met. Metallogr. 111, 314 (2011).

[10] A.A. Goncharov, V.A. Konovalov, S.N. Dub, V.A. Stupak, V.V. Petukhov, Phys. Met. Metallogr. 107, 285 (2009).

[11] P.H. Mayrhofer, C. Mitterer, J.G. Wen, I. Petrov, J.E. Greene, J. Appl. Phys. 100, 044301 (2006).

[12] A.A. Goncharov, S.N. Dub, A.V. Agulov, Phys. Met. Metallogr. 114, 95 (2013).

[13] M. Zhou, M. Nose, K. Nogi, Surf. Coat. Technol. 183, 45 (2004).

[14] C. Paternoster, A. Fabrizi, R. Cecchini, S. Spigarelli, Ph.V. Kiryukhantsev-Korneev, A. Sheveyko, Surf. Coat. Technol. 203, 736 (2008).

[15] M. Zhou, M. Nose, Y. Makino, K. Nogi, Thin Solid Films 343-344, 234 (1999).

[16] M.K. Bukhovets, I.V. Svadkovski, D.A. Golosov, S.M. Zavadski, in: Proc. Int. Conf. "Modification of properties of surface layers of non-semiconducting materials using particle beams", Sumy 1999, p. 48.

[17] D.V. Shtanskii, S.A. Kulinich, E.A. Levashov, J.J. Moore, Phys. Solid State 45, 1177 (2003).

[18] D.V. Shtansky, F.V. Kiryukhantsev-Korneev, A.N. Sheveiko, I.A. Bashkova, O.V. Malochkin, E.A. Levashov, N.B. D'yakonova, I.V.Lyasotsky, Phys. Solid State 47, 252 (2005).

[19] O.V. Sobol', S.N. Dub, O.N. Grigoryev, A.N. Stetsenko, A.A. Podtelezhnikov, J. Superhard Mater. 5, 38 (2005)

[20] S. Jayaraman, J.E. Gerbi, Y. Yang, D.Y. Kim, A. Chatterjee, P. Bellon, G.S. Girolami, J.P. Chevalier, J.R. Abelson, Surf. Coat. Technol. 200, 6629 (2006). 